\title{
A complexidade rítmica no Estudo Percussivo 11 de Arthur Kampela
}

\author{
Daniel Vargas (EMBAP, Curitiba, PR) \\ danielvargascoelho@yahoo.com.br
}

\begin{abstract}
Resumo: Este artigo discute 0 uso das estruturas ritmicas complexas, tais como quiálteras dentro de quiálteras na obra Estudo Percussivo II, de 1993, do compositor brasileiro Arthur Kampela. Em alguns casos, serão demonstrados procedimentos de notação da escrita complexa do compositor britânico Brian Ferneyhoug. Isso se dá pelo fato de ao transformar uma semínima em uma quiáltera de cinco, Ferneyhough utiliza uma simbologia acima da quiáltera, indicando que são cinco semicolcheias no lugar de quatro semicolcheias, desta forma, o compositor britânico faz a indicação da mesma figura rítmica ao utilizar a semicolcheia. Diferentemente, Arthur Kampela no Estudo Percussivo II, utiliza uma escrita peculiar na qual ele não faz a mesma indicação das figuras ritmicas como Brian Ferneyhough. Este artigo propõe uma discussão a respeito desta escrita peculiar no Estudo Percussivo II. Para finalizar será abordada a escrita complexa sobre a ótica de outros compositores como Pierre Boulez para que a partir desta visão sejam propostas outras possibilidades de escrita rítmica no Estudo Percussivo II.
\end{abstract}

Palavras-chave: Nova Complexidade, ritmos complexos, Música de Vanguarda, composição e performance.

\section{The rhythmic complexity in Percussion Study II by Arthur Kampela}

Abstract: This article discusses the use of complex rhythmic structures, such as tuplets within triplets in piece Percussion Study II, of 1993, by the Brazilian composer Arthur Kampela. In some cases, it will be shown notational procedures of complex writing by British composer Brian Ferneyhoug. By turning a quarter note in one of five tuplet, Ferneyhough uses an above the tuplet symbology, indicating that there are five sixteenth notes instead of four sixteenths; the British composer thus uses an indication of the same rhythmic figure, using the sixteenth note. In Percussion Study II, Arthur Kampela uses a peculiar writing in which he does the same indication of rhythmic figures such as Brian Ferneyhough. This article proposes a discussion about this peculiar writing in Percussion Study II and finally there will be shown the complex script from the standpoint of other composers such as Pierre Boulez, and from this vision, will be offered other possibilities notational Percussion in Study II.

Keywords: New Complexity, complex rhythms, avant-garde, composition and performance.

"A beleza da vida não está no início nem no fim e sim na travessia" (Guimarães Rosa)

\section{1 - Introdução}

0 presente artigo propõe uma discussão do uso de estruturas rítmicas complexas, tais como quiálteras dentro de quiálteras no Estudo Percussivo // de Arthur Kampela. Em 1990, o compositor brasileiro Arthur Kampela inicia a série Estudos Percussivos para violão, nessas peças o compositor brasileiro trabalha com o alargamento das possibilidades técnicas do instrumento. Kampela reinventa a maneira de execução do instrumento, na qual funde o modo tradicional de execução do violão com nuances percussivas, e produção de efeitos utilizando-se lápis, colher, sussurros com a voz, afinação micro tonal, viola (de orquestra) e cello tocados como violão e estruturas rítmicas complexas.

Ao utilizar um ponto de vista mais superficial, defendese que o Estudo Percussivo II pode ser estruturado em três partes. A primeira parte inicia com uma colher que realiza um glissando ascendente, seguido por um 
trecho de massa sonora. A segunda é o trecho no qual se encontra a seção das quiálteras, que será o foco deste texto. Na terceira e última parte, Kampela utiliza um lápis que realiza glissandos ascendentes e descendentes e rasgueados frenéticos e ainda, para finalizar, uma colher é utilizada para simular um som de uma guitarra elétrica ligada a um pedal de wah-wah.

É na segunda parte da obra que o compositor brasileiro emprega a escrita de estruturas rítmicas complexas e de compassos irracionais, ou como denomina o próprio Kampela, compassos não-integrais, (KAMPELA, 1999, p.191-192). Há uma peculiaridade na grafia de Kampela ao utilizar quiálteras dentro de quiálteras. Em muitos casos o compositor não faz a indicação das mesmas figuras rítmicas, há trechos em que escreve uma quiáltera [3:4], três colcheias no tempo de quatro semicolcheias, ao invés de escrever [6:4], seis semicolcheias no tempo de quatro semicolcheias, ou [3:2], três colcheias no tempo de duas colcheias.

Graziela Bortz finaliza seu artigo, "Modulação micrométrica na música de Arthur Kampela" com uma discussão em torno da notação utilizada pelos compositores da Escola da Nova Complexidade, tendo como precursor o compositor britânico Brian Ferneyhough, cujas obras possuem uma escrita extremamente detalhista e complexa. "É verdade que a alta precisão da notação oferece ao próprio compositor um grau de 'controle' que é apenas aparente do ponto de vista da realização no momento da performance"(BORTZ, 2006, p.1). Também se observa a mesma discussão referente à escrita em outras ocasiões, como em uma entrevista na qual o compositor francês Pierre Boulez faz críticas severas aos compositores da Escola da Nova Complexidade, sobretudo a Brian Ferneyhough. Boulez argumenta que é adepto a um grau de complexidade no momento da escrita, não obstante, uma complexidade que seja pelos músicos imaginável, decodificável e realizável. É neste ponto que ele ataca a notação de Brian Ferneyhough, argumentando que o compositor britânico emprega em suas obras redes de relações tão complexas, tais como quiálteras dentro de quiálteras, que a mente humana não é capaz de pensar. Pierre Boulez argumenta a enorme defasagem entre 0 que os compositores escrevem e o que os intérpretes reproduzem, como se pode observar no trecho a seguir:

\footnotetext{
"Na verdade, os músicos, quando se deparam com algo impossivel, realizam seus cálculos aproximativos e, no caso de coisas, simplesmente dizem: "Um pouco depois de 1; um pouco antes de 3; bem, aqui, neste caso mais ou menos no meio!..." No final das contas, tem-se aproximações extremamente grosseiras com relação a coisas que são em si irrealizáveis". (BOULEZ, 2006, p.218)'.
}

\section{2 - Indicação das mesmas figuras rítmicas}

Neste primeiro momento é importante demonstrar como funciona o procedimento de indicação das mesmas figuras ritmicas. Observe o Ex.1 a seguir.

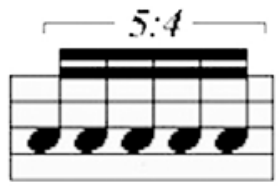

Ex.1 - Quiáltera de cinco, cinco semicolcheias no lugar de quatro semicolcheias.

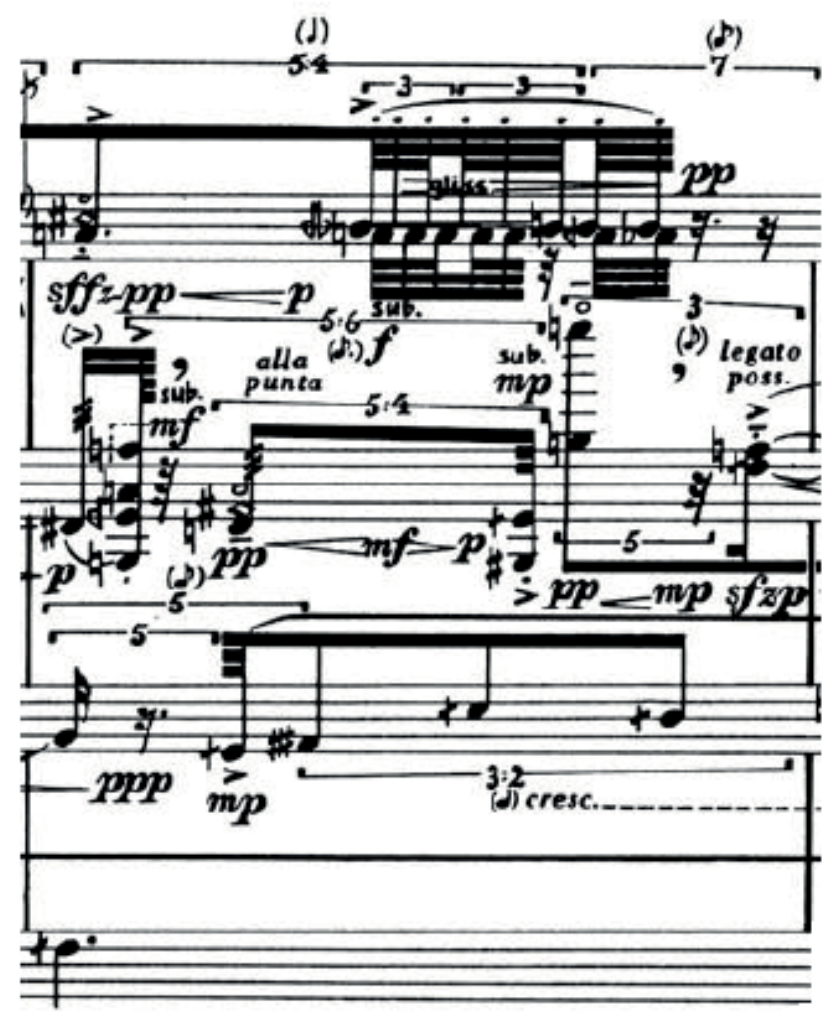

Ex.2 - Adagissimo para quarteto de cordas, de Brian Ferneyhough, c.11, indicação das mesmas figuras rítmicas. 
No Ex.1 acima há uma quiáltera de cinco semicolcheias e logo acima dela encontra-se dois algarismos, 5 e 4, [5:4]. Os algarismos 5 e 4 fazem referência a semicolcheia, ou seja, são 5 semicolcheias no tempo de quatro semicolcheias. Pode-se observar esse procedimento notacional em obras de Brian Ferneyhough, como demonstra o Ex.2 a seguir.

Observe o Ex.2 acima, primeiro violino, c.11, primeira quiáltera, [5:4]. Os algarismos 5 e 4 fazem referência à semicolcheia, ou seja, são cinco semicolcheias no tempo de quatro semicolcheias.

\section{3 - A escrita complexa de quiálteras dentro de quiálteras}

0 princípio da escrita de figuras rítmicas complexas se dá através da utilização de quiálteras dentro de quiálteras, como mostra o Ex.3 a seguir.

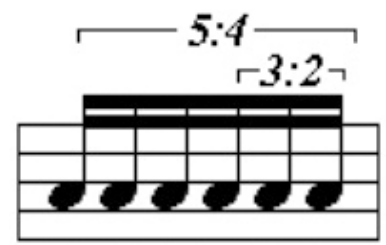

Ex.3 - Quiáltera dentro de quiáltera.

No Ex.3, há duas quiálteras verticalmente sobrepostas, uma em um nível primário representado pelos algarismos 5 e 4, [5:4] e outra em um nível secundário representado pelos algarismos 3 e 2, [3:2]. Primeiramente, transformase uma semínima que contém quatro semicolcheias em uma quiáltera de cinco, conforme o Ex.4 que se segue.

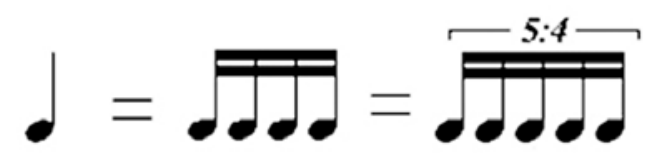

Ex. 4 - Transformação da semínima em quiáltera de cinco.

No Ex.4, os números 5 e 4 fazem referência a mesma figura rítmica, ou seja, são cinco semicolcheias no lugar de quatro semicolcheias. Em seguida, para criar uma nova quiáltera dentro da quiáltera de cinco, uma das possibilidades é transformar as duas últimas semicolcheias da quiáltera de cinco em uma tercina, (Ex.5 a seguir).

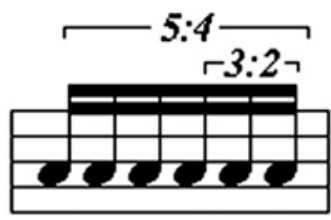

Ex.5 - Transformação das duas últimas semicolcheias da quiáltera de cinco em uma tercina.

Na quiáltera secundária [3:2], (Ex.5 anterior), os algarismos 3 e 2, fazem referência a mesma figura rítmica, ou seja, são três semicolcheias no lugar de duas semicolcheias. Observa-se que o procedimento de sobrepor quiálteras é a princípio o mesmo. Em primeiro plano, transformamse quatro semicolcheias em cinco semicolcheias, em seguida, as duas últimas semicolcheias da quiáltera de cinco em uma tercina.

Atente-se que no Ex.5 a figura possui dois níveis, um nível primário representado pela quiáltera [5:4] e um nível secundário representado pela quiáltera [3:2]. Neste exemplo encontram-se duas quiálteras sobrepostas verticalmente. No decorrer do artigo será demonstrado que ouve uma aceleração metronômica das figuras, pois as semicolcheias das quiálteras de [5:4] e [3:2] possuem velocidades metronômicas diferentes.

\section{4 - A não indicação das mesmas figuras rítmicas no Estudo Percussivo II de Arthur Kampela}

No Estudo Percussivo I/ (1993), de Arthur Kampela, há uma peculiaridade notacional quando o compositor trabalha com a escrita rítmica complexa de quiálteras dentro de quiálteras. Em muitos casos Kampela escreve [3:4], três colcheias no tempo de quatro semicolcheias, ao invés de [6:4], seis semicolcheias no tempo de quatro semicolcheias, nesse último caso, tanto o algarismo seis quanto o algarismo 4 são referentes a semicolcheias. Logo no início da obra, mais precisamente na parte que se inicia a seção das quiálteras, página 6, c.2, há duas quiálteras em nível primário, [8:5] e [7:3], ver Ex.6.

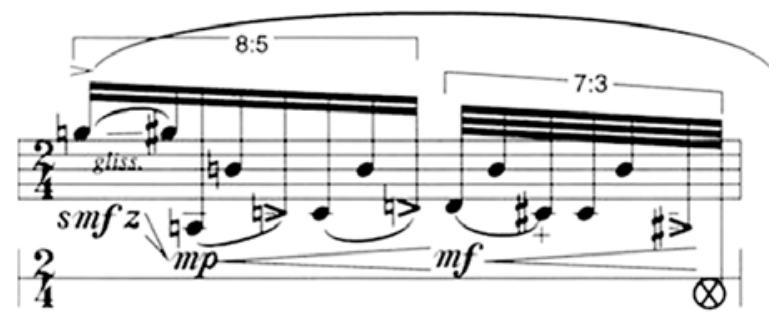

Ex.6 - Estudo Percussivo II, para Violão solo, (1993) de Arthur Kampela, c.2, quiálteras primárias.

Na primeira quiáltera [8:5], tanto o algarismo 8 quanto o algarismo 5 fazem referência a mesma figura rítmica que é a semicolcheia, são oito semicolcheias no tempo de cinco semicolcheias. Na quiáltera [8:5] há cinco semicolcheias, portanto, ainda faltam três semicolcheias para completar um total de oito semicolcheias no compasso 2/4. As últimas três semicolcheias do c.2 são transformadas em uma quiáltera de sete que está representada pelos números 7 e 3, [7:3]. Não obstante, os algarismos 7 e 3 não fazem referência a mesma figura rítmica, pois o número 7 é referente a fusa e o número 3 é referente a semicolcheia, ou seja, são sete fusas no tempo de três semicolcheias. Kampela poderia optar por fazer referência a mesma figura, direcionando os dois algarismos a fusa, [7:6], nesse caso, tanto o sete quanto o seis se referem à fusa, sete fusas no tempo de seis fusas.

No c.5, (Ex.7), há outro exemplo de não indicação das mesmas figuras rítmicas, neste trecho há um compasso [3/4] com três quiálteras primarias [7:4], [3:4] e [5:4]. 


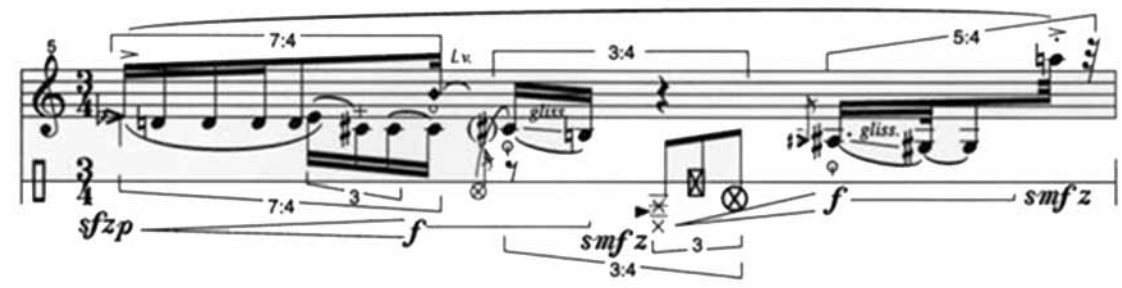

Ex. 7- Estudo Percussivo II, para Violão solo, (1993) de Arthur Kampela, c.5.

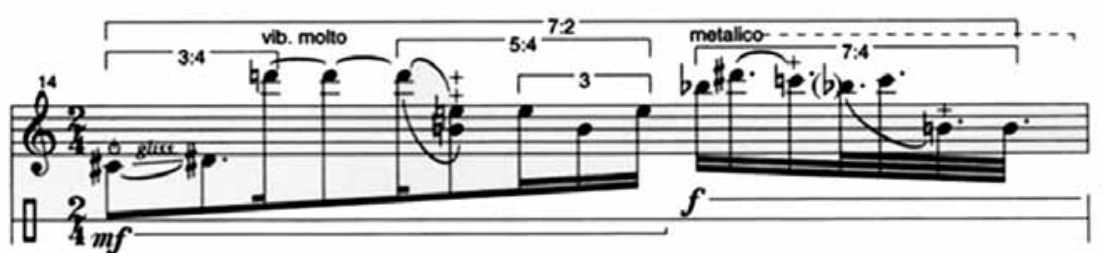

Ex. 8- Estudo Percussivo II, para Violão solo, (1993) de Arthur Kampela, c.14.

No Ex.7, tanto na primeira quiáltera [7:4] quanto na terceira quiáltera [5:4] não há problemas no que diz respeito à indicação das mesmas figuras rítmicas, na quiáltera [7:4] são sete semicolcheias no tempo de quatro semicolcheias e na quiáltera [5:4] são cinco semicolcheias no tempo de quatro semicolcheias. Não obstante, na segunda quiáltera [3:4] os algarismos 3 e 4 não condizem com a mesma unidade ritmica, pois o algarismo 3 relaciona-se com a colcheia, enquanto o algarismo 4 relaciona-se com a semicolcheia. Arthur Kampela poderia optar por escrever [6:4], seis semicolcheias no tempo de quatro semicolcheias, ou [3:2], três colcheias no tempo de duas colcheias.

Quando há quiálteras em dois ou mais níveis de complexidade, o intérprete precisa ser cauteloso no momento da leitura, ver Ex.8 a seguir.

Conforme o Ex.8, encontra-se no c.14 uma quiáltera primária, [7:2] que abarca todo o compasso, Kampela transforma um compasso [2/4] em um [7/8], não obstante com uma semínima de valor metronômico diferente, calcularemos essas diferenças de velocidades metronômica mais adiante.

Uma das possibilidades de interpretação para a quiáltera [7:2] é a que o número 7 faz referência à colcheia e o número 2 é referente à mínima, ou seja, são sete colcheias no tempo de uma mínima, uma outra interpretação para a quiáltera [7:2], é que ela é uma fração inversa, 2:7, ou seja, o algarismo 2, mínima, foi dividida (desviada) em sete partes iguais, sete colcheias. Ainda no Ex.8, na primeira quiáltera secundária [3:4] encontra-se a mesma questão suscitada na quiáltera primária [7:2]. 0 algarismo 3 refere-se a colcheia enquanto que o algarismo 4 refere-se a semicolcheia, Arthur Kampela poderia optar por utilizar [6:4], seis semicolcheias no espaço de quatro semicolcheias ou [3:2], três colcheias no espaço de duas colcheias. Observe que as duas propostas fazem referência a mesma figura, [6:4] diz respeito à semicolcheia enquanto [3:2] faz menção à colcheia, veja o que o compositor dos Estudos Percussivos argumenta sobre esse procedimento:

\begin{abstract}
"Por exemplo, a razão [3:4], no segundo nível da subdivisão, implica que o número 4 não só é designado para quatro semicolcheias, mas também para a métrica representativa de uma semínima. Quando encontramos desvios que acontecem contra os números $2,4,8,16$, nós os interpretamos como desvios que ocorrem de uma semibreve, uma semínima, fusa e semifusa, respectivamente. Observe que a quinta semicolcheia, não desviada, na primeira quiáltera [7:5] não é interpretada como uma métrica específica desde que ela não seja multiplicação ou divisão do pulso. Portanto, nós simplificamos a escrita dos números, contra os quais o número da esquerda é desviado". (KAMPELA, 1998, p.36-37).
\end{abstract}

\section{5 - A utilização de figuras para ajudar no cálculo}

No Estudo Percussivo III (1998) de Arthur Kampela, em alguns casos, ainda há exemplos de não indicação das mesmas figuras, no entanto o compositor utiliza mínimas, semínimas, colcheias e semicolcheias, acima das quiálteras para facilitar a contagem do intérprete. Pode-se observar o mesmo procedimento em obras do compositor Brian Ferneyhough, ver Ex.9 a seguir.

Observe no Ex.9 que nas duas primeiras quiálteras primárias, [5], no violino 1, há uma colcheia acima de cada uma delas, esta colcheia pode ajudar o intérprete a 


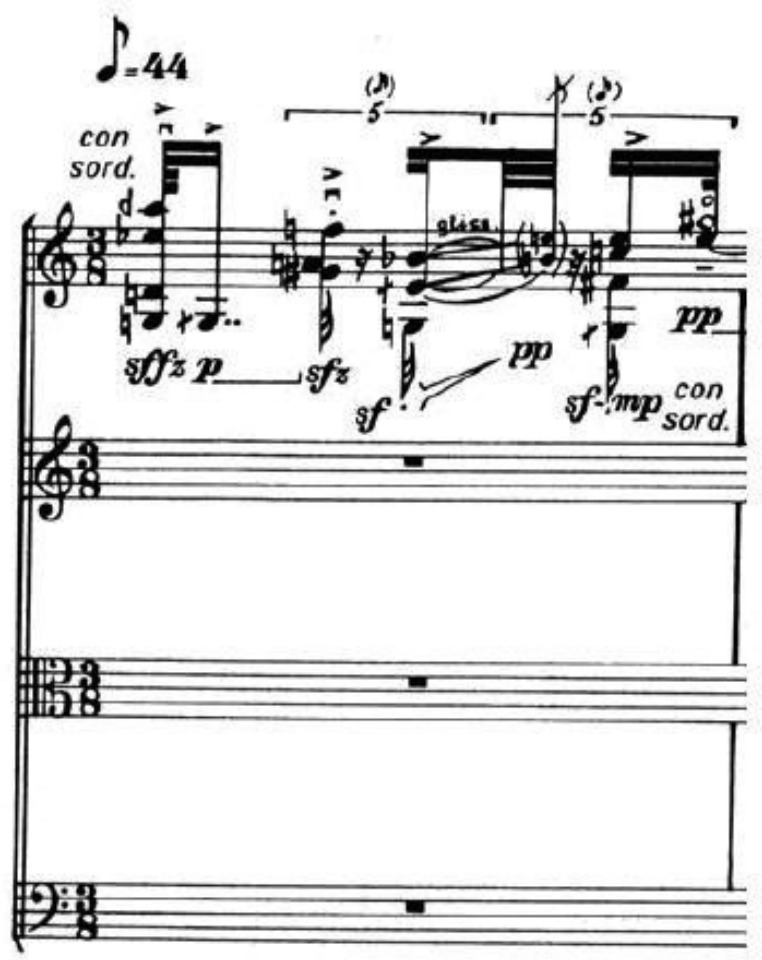

Ex.9 - Adagissimo para quarteto de cordas, de Brian Ferneyhough, figuras rítmicas acima das quiálteras primárias para auxiliar no cálculo.

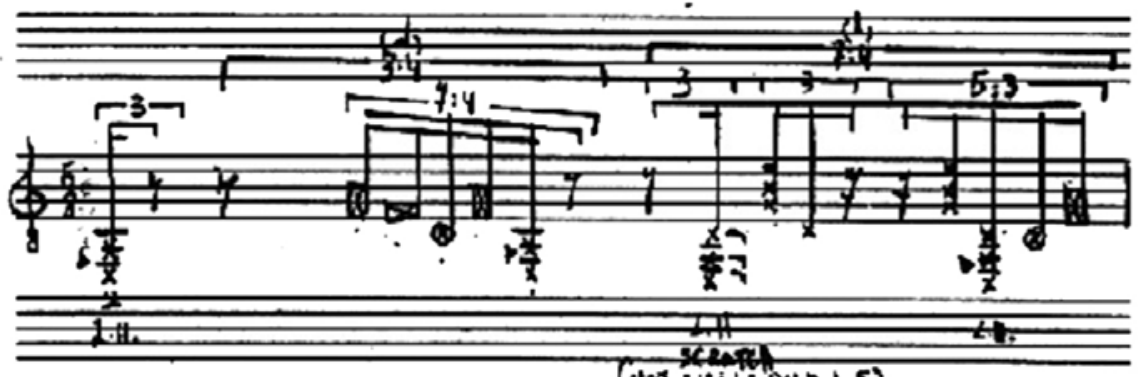

(Usi Whibs on $b, b_{1}$, )

Ex.10 - Arthur Kampela, Estudo Percussivo III, para violão solo, (1998), variação I, c.32.

calcular que são cinco fusas no tempo de quatro fusas. Kampela utiliza o mesmo procedimento notacional no Estudo Percussivo III, de 1998, ver Ex.10 a seguir.

No Ex.10 anterior, na segunda quiáltera primária [3:4] há três colcheias no lugar de quatro semicolcheias, ou seis semicolcheias no lugar de quatro semicolcheias, [6:4], ou ainda, três colcheias no lugar de duas colcheias, [3:2]. A semínima acima da quiáltera primária [3:4] pode auxiliar o intérprete a decodificar a estrutura e certificar que no total há uma semínima ou quatro semicolcheias na quiáltera.

No início do c.7, Estudo Percussivo III, (Ex.11 a seguir), encontra-se na quiáltera primária [8:5], oito semicolcheias no tempo de cinco semicolcheias e acima dessa quiáltera há uma semínima em ligadura com uma semicolcheia, 0 que facilita a compreensão que são oito semicolcheias no tempo de cinco semicolcheias. Há também uma quiáltera secundária [3:4], três colcheias no tempo de quatro semicolcheias, ou [6:4] seis semicolcheias no tempo de quatro semicolcheias (Ex.11 a seguir).

Neste Ex.11, caso o algarismo três da estrutura secundária [3:4] provoque alguma dúvida, o intérprete pode observar que há uma semínima em tremolos, logo após a figura [3:4]. Lembre-se de que a semínima faz parte da quiáltera primária [8:5], desta forma, pode-se pensar: se há oito semicolcheias e já temos certeza que há uma semínima dentro da quiáltera, (tremolos), então a outra semínima que falta para completar a figura primaria [8:5] é alterada formando a estrutura secundária [3:4] ou [6:4]. 


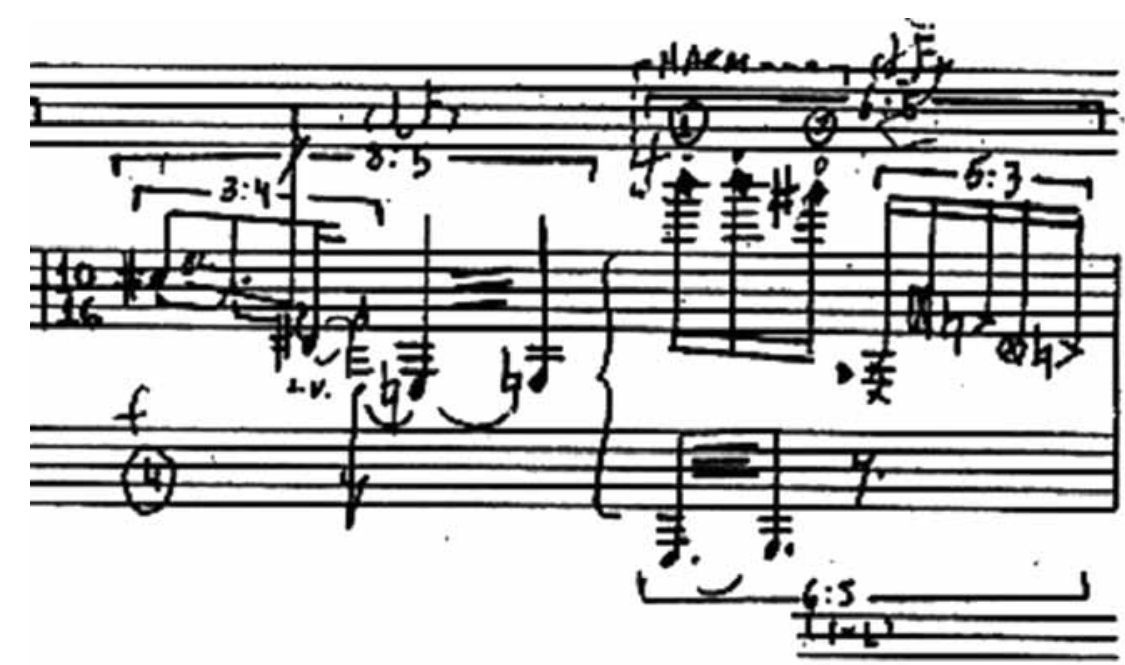

Ex.11 - Arthur Kampela, Estudo Percussivo III, para violão solo, (1998) variação I, c.7.

\section{6 - Cálculo da mudança de velocidade}

Aprender a calcular a semínima da quiáltera, como será demonstrado a seguir, pode ser uma ferramenta importante para o intérprete no momento do estudo de obras que possuem uma escrita complexa, como o Estudo Percussivo II. Para a explicação dos cálculos me apoio no modelo demonstrado por Graziela Bortz em sua tese de doutorado "Ritmo na música de Brian Ferneyhough, Michael Finissy e Arthur Kampela: um guia para intérpretes" (CUNY, 2003) e em seu artigo: "Modulação micrométrica na música de Arthur Kampela", publicado na Revista Per Musi em 2006.

No Ex.12 há uma quiáltera primária [5:4], cuja semínima equivale a $70 \mathrm{MM}$, ou seja, as cinco semicolcheias serão executadas em uma pulsação de $70 \mathrm{MM}$. A operação ensina a calcular quanto será o novo pulso (X MM), no qual se executa a semínima, ou quatro semicolcheias da quiáltera de cinco. Primeiramente toma-se o pulso $70 \mathrm{MM}$ multiplicado pelo algarismo 5 e depois dividido pelo algarismo 4: $70 \mathrm{MM} \times$ 5:4= 87.5 MM. De acordo com a operação, a semínima ou quatro semicolcheias da quiáltera de cinco serão executadas em um pulso de 87.5 MM, caso o intérprete não possua um metrônomo fracionado, ele pode arredondar para $88 \mathrm{MM}$. Lembre-se de que neste caso, por princípios matemáticos, trabalhase com números que contemplem a mesma unidade de medida, ou mesma figura rítmica, ou seja, os algarismos 5 e 4 fazem referência a semicolcheia.

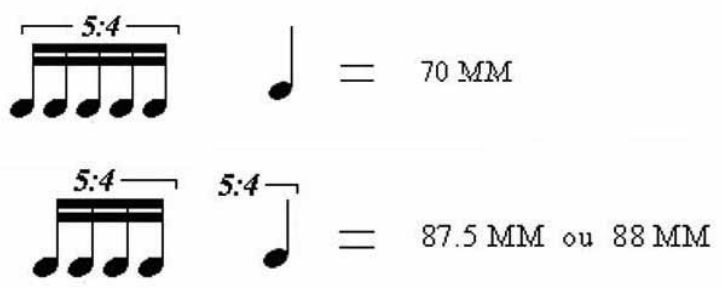

Ex.12 - Cálculo da semínima da quiáltera de cinco.
Pode-se utilizar esse mesmo procedimento para se obter as velocidades metronômicas das semínimas das quiálteras secundárias. No c.20 do Estudo Percussivo II há uma quiáltera primária [9:7], nove semicolcheias no tempo de sete semicolcheias, ver Ex.13 a seguir.

Utilizando o Ex.12 que demonstra o cálculo da mudança de velocidade, é possível perceber que primeiramente calcula-se a semínima da quiáltera primária [9:7], 70 MM $\times$ 9:7 = 90 MM. ${ }^{1}$ Em seguida, para descobrir o valor da semínima da quiáltera secundária [3:4] utiliza-se o valor da nova semínima da quiáltera [9:7], $90 \mathrm{MM}$ multiplicado por seis e depois dividido por quatro: 90 $\mathrm{MM} \times 6: 4=135 \mathrm{MM}^{2}$ Por uma questão matemática, o algarismo 3 precisa ser trocado pelo 6, [6:4], veja o que Graziela Bortz argumenta a respeito da troca dos algarismos das quiálteras, faz-se oportuno mencionar que o exemplo citado é referente à obra Phalanges, para Harpa solo, (1995) de Arthur Kampela.

\footnotetext{
"Observe que, na quiáltera [7:2], no segundo compasso, os números não fazem referência aos mesmos valores rítmicos. Aqui, sete colcheias substituem duas semínimas, (ou sete colcheias substituem quatro colcheias.) Assim, a velocidade dessas colcheias será traduzida para a fração 4/7. Na quiáltera, ou compasso, de símbolo $2 / \delta, j$, a colcheia da quiáltera de sete representa a unidade de pulso. Em outras palavras, nós mantemos aqui a mesma relação em que sete colcheias substituem as quatro colcheias normais; portanto, nós obtemos a fração igual a 4/7. Isso prova que a semicolcheia da quiáltera primária [7:2] e as da estrutura $2 /$ [1] dividem a mesma velocidade". (BORTZ, 2003, p.90-91).
}

Pode-se utilizar o mesmo procedimento para calcular a semínima da quiáltera secundária [5:3]. Então, primeiramente multiplicamos o valor da semínima da quiáltera [9:7], (90 MM) por cinco e depois dividimos por três, $90 \mathrm{MM} \times 5: 3=150 \mathrm{MM}$. Também existe a possibilidade de calcular o pulso no qual toda a quiáltera [5:3] será executada, o primeiro passo é utilizar o pulso 


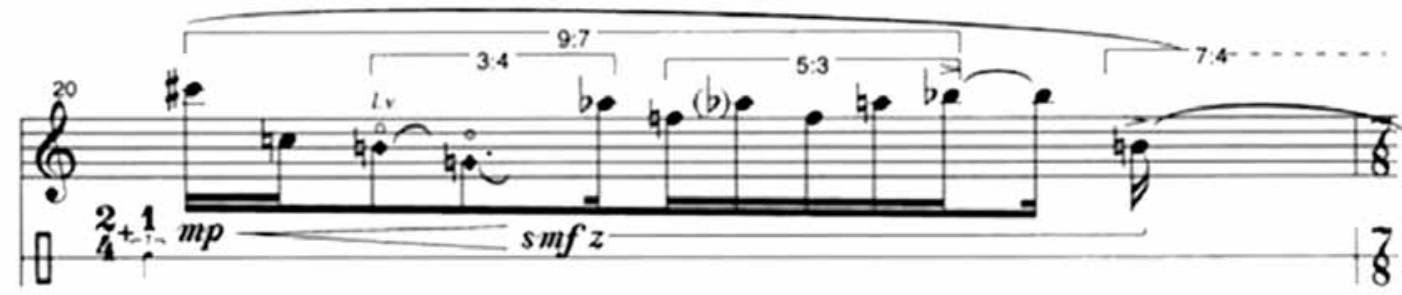

Ex. 13- Estudo Percussivo II, para Violão solo, (1993) de Arthur Kampela, c.20.

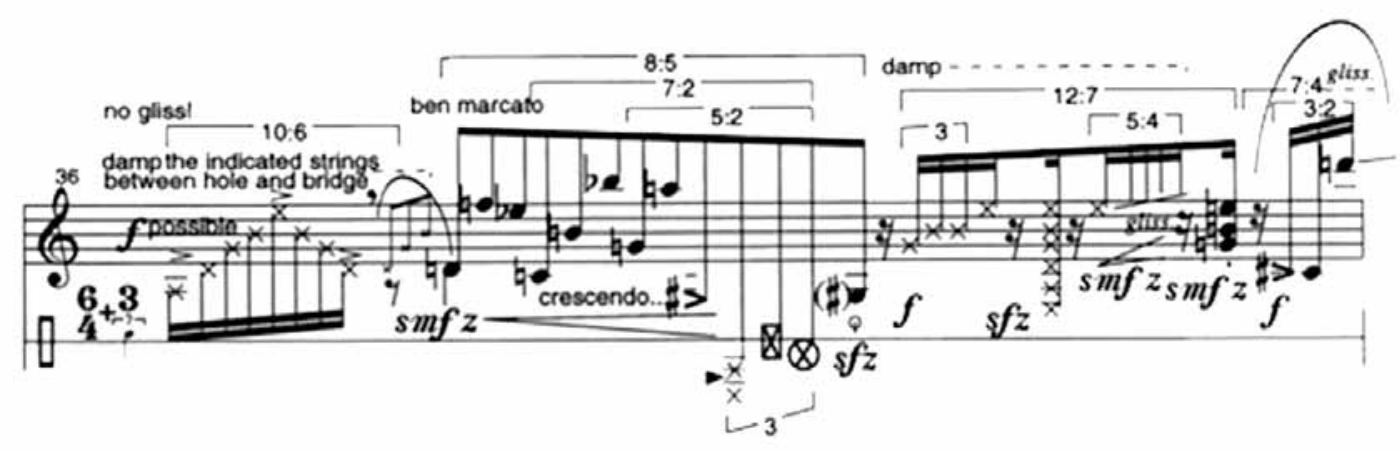

Ex.14 - Estudo Percussivo II, para Violão solo, (1993) de Arthur Kampela, c.36.

da quiáltera [9:7], (90 MM) multiplicá-lo por quatro e depois dividí-lo por três, $90 \mathrm{MM} \times 4: 3=120 \mathrm{MM}$, de acordo com a operação, 120 MM será a pulsação na qual toda a quiáltera [5:3] será executada.

No c.36 do Estudo Percussivo II, a segunda quiáltera possui quatro estratos, [8:5], [7:2], [5:2] e [3:2], ver Ex.14 a seguir.

De acordo com os cálculos demonstrados anteriormente é possível calcular a semínima de cada quiáltera do Ex.14. Para a primeira quiáltera [8:5]: multiplicamos o andamento inicial da peça $70 \mathrm{MM}$ por oito e depois dividimos por cinco: $70 \mathrm{MM} \times 8: 5=112$ MM. Para a segunda quiáltera [7:2], vale lembrar que por uma questão matemática, é preciso trocar o algarismo 2 por 4, [7:4], sete colcheias no tempo de quatro colcheias e não sete colcheias no tempo de duas semínimas, o que resulta em: $112 \mathrm{MM} \times$ 7:4=196 MM e para a terceira quiáltera [5:2] o cálculo segue a mesma linha de raciocínio, qual seja [5:4], cinco colcheias no lugar de quatro colcheias, $196 \mathrm{MM} \times$ 5:4=245 MM, por fim a última quiáltera 3 abarca três colcheias em um pulso de 245 MM.

Como demonstrado nos cálculos acima, houve uma aceleração metronômica da semínima, observe o Ex.15 a seguir.

\begin{tabular}{|l|ll|}
\hline Grupo [8:5] & Semínima $=112 \quad$ MM \\
\hline Grupo [7:2] & Semínima $=196 \quad$ MM \\
\hline Grupo [5:2] & Semínima $=245 \quad$ MM \\
\hline Grupo [3] & Semínima $=375,5 \mathrm{MM}$ \\
\hline
\end{tabular}

Ex.15 - Aceleração metronômica da semínima.
Quando há redes com até quatro niveis de complexidade como no c.36 do Estudo Percussivo II, a construção de tabelas que demonstrem o resultado dos cálculos para obtenção da semínima, pode ser importante para se obter uma maior aproximação do ritmo que os compositores escrevem. De acordo com as operações matemáticas e os resultados expressos no Ex.15, observa-se que houve uma aceleração metronômica da semínima.

Pierre Boulez, em uma entrevista, comenta a impossibilidade da racionalização de certas relações que envolvem até três níveis de complexidade.

\footnotetext{
"Temos, por exemplo, a figura de sete no lugar de cinco; no interior dos sete, opta-se, por exemplo, por cinco no lugar de quatro e como ainda sobram três valores, escreve-se então sete no lugar de três. Ora, é evidente que não podemos pensar em redes de relações dessa espécie! É algo simplesmente impossivel, pois não se pode mais que uma relação de cada vez: você pensa em uma relação de sete no lugar de cinco, após o que não é possivel fazer mais nada! A solução desse tipo de problema - aliás, bem simples -, visando a um resultado semelhante, é, pois, pensar em uma mudança de velocidade". (BOULEZ, 2006, p.217).
}

Para Pierre Boulez, a opção por uma mudança de velocidade é uma alternativa mais simples do que pensar em três ou mais planos sobrepostos. Para ilustrar, mostraremos a estrutura com três níveis verticais que Boulez descreve no trecho anterior e logo, vamos "esmiuçá-la" e realizar a mudança de velocidade como propõe o compositor francês, ver Ex.16 e Ex.17 a seguir. 


\section{7 - Outras possibilidades de notação}

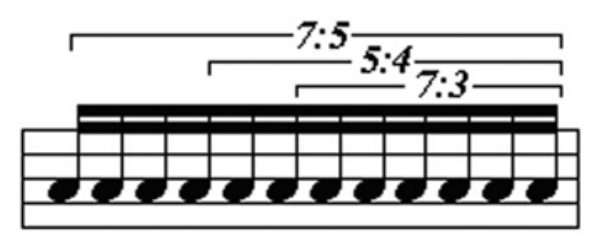

Ex.16 - Quiáltera descrita por Pierre Boulez.

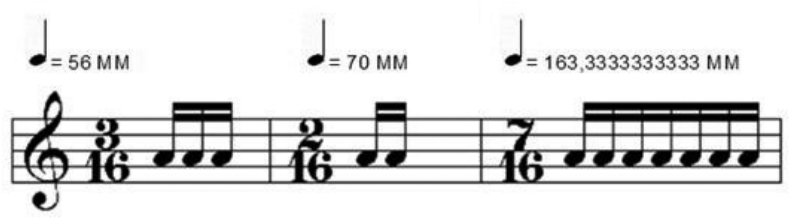

Ex.17 - Mudança de velocidade proposta por Pierre Boulez.

Conforme demonstrado no Ex.16 e 17, houve a transformação de três níveis sobrepostos verticalmente, [7:5], [5:4] e [7:3], em três compassos na horizontal, não obstante para cada compasso a semínima possui um valor metronômico diferente. 0 primeiro passo foi calcular a velocidade metronômica da semínima de cada quiáltera, [7:5]: $40 \mathrm{MM} \times$ 7:5=56 MM, [5:4]: $56 \mathrm{MM} \times 5: 4=70$ MM e [7:3]: $70 \mathrm{MM} \times$ 7:3=163.33333333333 MM. ${ }^{3} 0$ segundo passo foi "desobrepor" as quiálteras e colocálas horizontalmente em três compassos diferentes, como demonstrado no Ex.17 anteriormente.

Tendo como base o c.26 do Estudo Percussivo II, vamos aprofundar na proposta de mudança da velocidade de Pierre Boulez. Tentaremos eliminar, por etapas, as quiálteras sobrepostas e reescrever o compasso com 0 mínimo de quiálteras uma dentro da outra. De acordo com Pierre Boulez os músicos não podem pensar mais que uma relação de cada vez, por isso tentaremos fazer com que o c.26, que possui até três níveis de complexidade, passe a ter somente quiálteras primárias.

No Ex.18, há um compasso [7/8] com quiálteras de três níveis de complexidade. Tentaremos eliminar os níveis verticais e mudar a velocidade da semínima, como propõe Pierre Boulez. 0 primeiro passo será calcular a semínima da quiáltera primaria [9:7]: $70 \mathrm{MM}$ × 9:7=90 MM. De acordo com Pierre Boulez, se for indicado um signo de compasso [9/8], com a semínima equivalente a $90 \mathrm{MM}$, a quiáltera primária [9:7], poderá ser eliminada, ver Ex.19 a seguir.

Observe que a quiáltera primária [9:7] do Ex.18 foi cancelada. Transformamos o compasso 7/8 em um 9/8 e a semínima passou de $70 \mathrm{MM}$ para $90 \mathrm{MM}$. Ainda há três quiálteras com níveis secundários e existe a possibilidade de eliminar as duas quiálteras primárias [5:4] do referido exemplo, se seguirmos a mesma proposta de mudança de velocidade. Para isso, é preciso fundir as quatro quiálteras [5:4] e transformá-las em uma larga quiáltera de [20:16], lembre-se de que são 20 semicolcheias no lugar de 16 semicolcheias e por fim, calcula-se o valor da semínima da quiáltera [20:16]: 90 MM x 20:16=112.5 MM. Observe o Ex.20.

No Ex.20, o compasso passou a ser um $5+5+5+5+2 / 16$ e a semínima passou de $90 \mathrm{MM}$ para $125.5 \mathrm{MM}$. Observe que no Ex.19, há quatro quiálteras de cinco, [5:4] e mais um agrupamento de três, [3:2]. A opção de escrever um compasso $5+5+5+5+2 / 16$ faz com que o intérprete ainda continue pensando em agrupamentos de cinco, como propõe Kampela, no c.26, do Estudo Percussivo II.

Mediante o exposto, para facilitar a compreensão é necessário organizar os compassos com suas respectivas mudanças de velocidade, de acordo com o Ex.21.

Atente-se que no Ex.21 os compassos ficaram organizados em $5+5+5+5 / 16$, com semínima equivalente a $125.5 \mathrm{MM}$ e 2/16, com a semínima equivalente a 90MM. Ao aplicar o raciocínio de mudança de velocidade de Pierre Boulez, utilizamos o c.26 do Estudo Percussivo // que contêm quiálteras em três niveis de complexidade e, por etapas modificamos cada um deles e a velocidade de suas respectivas semínimas.

No momento se faz interessante esclarecer que em uma conversa informal com o compositor e violonista Arthur Kampela, vale lembrar que ele é o próprio intérprete de suas obras para violão, Kampela me perguntou como eu havia resolvido o problema das quiálteras, no momento da leitura do Estudo Percussivo II, respondi que calculei matematicamente quase todas as quiálteras para uma maior aproximação rítmica, logo Kampela disse: "Tenha uma idéia da 'ESCULTURA RÍTMICA', isto é o mais importante. 0 ritmo não precisa ser perfeito, mas bem aproximado para valorizar a aparição dos efeitos, 0 tempo geral é flutuante dependendo da adrenalina no momento da performance".

\section{8 - Considerações finais}

Em seu artigo "Developing an interpretative context: learning Brian Ferneyhough's Bone Alphabet", tradução: Desenvolvendo um contexto interativo: lendo Bone Alphabet de Brian Ferneyhough, o percussionista Steven Schick aborda caracteristicas pertinentes de seu processo de aprendizado da obra para percussão solo do compositor britânico Brian Ferneyhough, veja um trecho a seguir, no qual Steven Schick discute aspectos rítmicos de Bone Alphabet:

"Eu penso que a idéia de aproximação implica em um 'processo de adivinhação' e, portanto, a aceitação da imprecisão rítmica". Adivinhar é outra forma de dizer que o último julgamento da precisão rítmica é o ouvido. $E$, por extensão, o ouvido, o meio tradicional de aprendizado, escuta, e verificação da precisão rítmica, ainda é de primordial importância no aprendizado, mesmo em ritmos muitos complexos. Eu poderia gerar gráficos polirritmicos dos minimos múltiplos comuns ou usar modelos por computador se eu quisesse (não fiz), mas, no fim, ouvidos humanos iriam julgar a performance, portanto ouvidos humanos devem guiar o processo de aprendizagem". (SCHICK, 1994, p.133). 


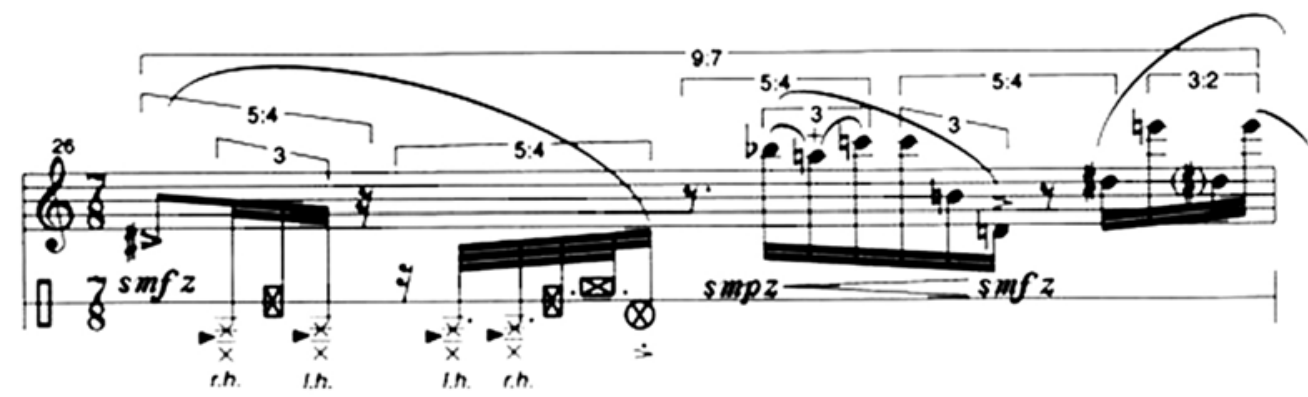

Ex.18 - Estudo Percussivo II, para Violão solo, (1993) de Arthur Kampela, c.26.

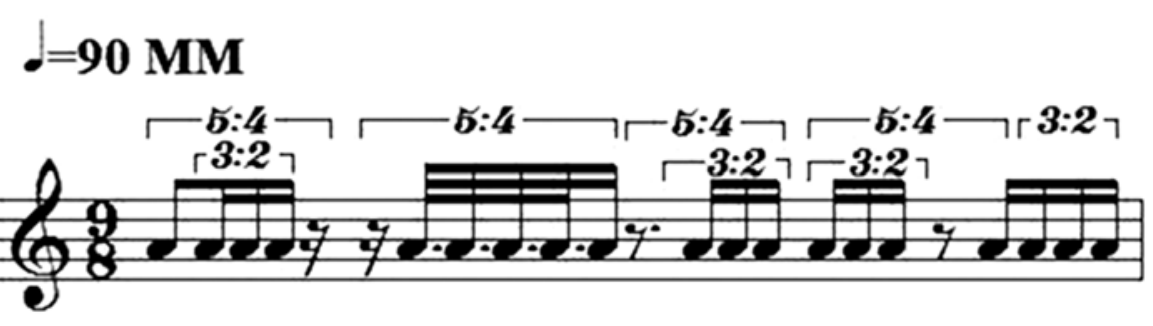

Ex.19 - Quiáltera primária excluída, semínima passando de 70 MM para 90 MM.

\section{$J=125,5 \mathrm{MM}$}

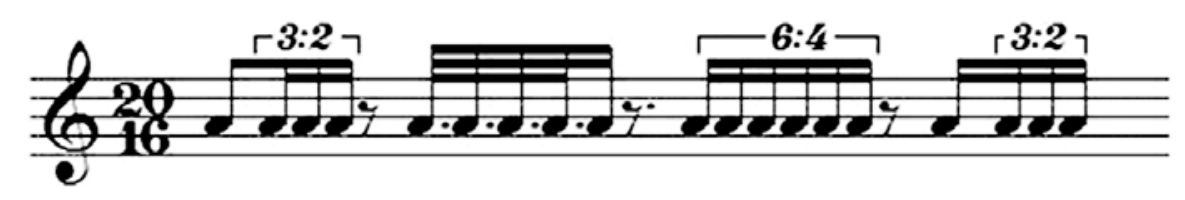

Ex.20 - Quiálteras secundárias excluídas.

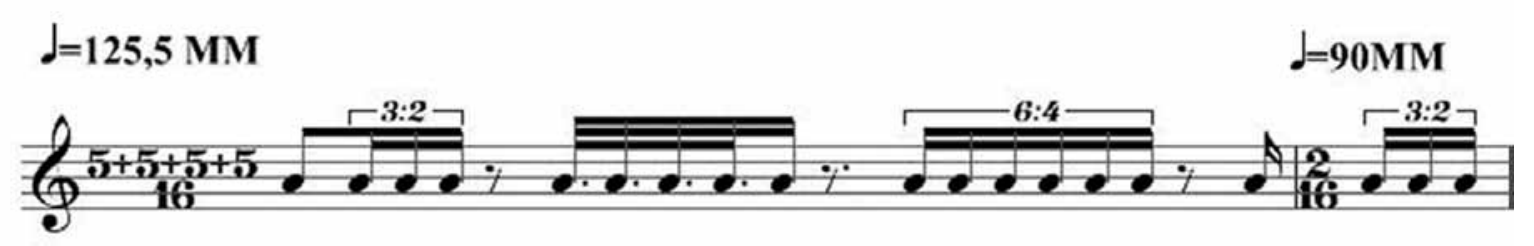

Ex.21 - Mudança de velocidade.

Do ponto de vista do intérprete que deseja estudar obras de compositores da Escola da Nova Complexidade, como as de Brian Ferneyhough e Arthur Kampela, o trecho anterior do artigo de Steven Schick, ou mesmo o termo cunhado por Kampela, "Escultura rítmica", pode ser muito importante, porque trabalhamos com uma música cuja escrita é complexa e precisa, mas essas características não podem fazer com que os intérpretes sintam-se amordaçados pelo alto grau de complexidade presente nas obras. Lidamos com uma música que pode estar além dos limites perceptivos e até físicos do ser humano, no entanto é importante levar em consideração, como diz Steven Schick, que o processo de aprendizado de obras como Bone Alphabet precisa ser nos limites humanos, ao mesmo tempo se esforçando ao máximo para respeitar a proposta dos compositores. 
"Ao contrário do que parece, a escrita abordada neste texto não pretende ser rigida e exata, e sim trabalhosa, admitindo em sua aritmética espaço para a inexatidão, para a complexidade, onde os fenômenos que ocorrem na execução, incluindo o matemático, interagem modificando cada performance. Assim como De Masi cre que as ciências exatas encontaram um nova oportunidade ao aceitar a inexatidão e complexidade, não somente das ciências humanas, más da própria natureza, também os intérpretes de música erudita podem incorporar ao continum aprendizado novas propostas criadas por compositores vivos, ainda que trabalhosas e, afinal, inexatas, mas não mais inexatas que a própria escrita tradicional". (BORTZ, 2006, p.98).

Quando percorremos a travessia da seção das quiálteras, do Estudo Percussivo /l de Arthur Kampela - a utlização das ferramentas matemáticas e da tabela pode ser muito importante para uma melhor orientação e aproximação rítmica no momento do estudo da obra, no mais não executamos a peça com as diferenças microrrítmicas e de microssegundos. Que as ferramentas presentes neste artigo sejam importantes para os intérpretes que desejam estudar as obras de compositores da Escola da Nova complexidade, sobretudo as de Arthur Kampela.

Quando foi proposto outros procedimentos notacionais, ao "confrontar" o pensamento notacional de Pierre Boulez com o de Brian Ferneyhough e ao reescrever o c.26, do Estudo Percussivo II, de Arthur Kampela não pretendo afirmar que uma maneira seja mais fácil ou melhor que outra. Cabe ao próprio intérprete adotar o critério que considerar de mais valia, quanto ao procedimento notacional, ao se depararm com obras que possuam uma escrita detalhista e complexa, como o Estudo Percussivo // de Arthur Kampela.

\section{Referências Bibliográficas}

BORTZ, Graziela. Rhythm in the Music of Brian Ferneyhough, Michael Finnissy, and Arthur Kampela: A Guide for Performers. New York: Graduate School and University Center of CUNY, 2003. (Tese de doutorado).

. Modulação micrométrica na música de Arthur Kampela. Per Musi, Belo Horizonte, n¹3, p.85-99, Jan/Jun. 2006.

BOULEZ, Pierre. Pierre Boulez no Studio PANaroma. In: Flo Menezes, Música Maximalista: ensaios sobre a música radical e especulativa. São Paulo: Editora UNESP, 2006. Entrevista concedida a Flo Menezes.

FERNEYHOUGH, Brian. Adagissimo para Quarteto de Cordas. Partitura. London: Peters, 1985.

KAMPELA, Arthur. Micro-Metric Modulation: New Directions in the Theory of Complex Rhythms. New York: Columbia University, 1998. (Tese de doutorado)

"A Knife All Blade: Deciding the Side Not to Take". Current Musicology, New York, n. 67- 68, p.167-193, Fall-winter 1999.

Estudo Percussivo II, para violão solo. Partitura. Manuscrito do autor, 1993.

Estudo Percussivo III, para violão solo. Partitura. Manuscrito do autor,1998.

Conversa informal entre Arthur Kampela e Daniel Vargas, via Skype. 24 de abril de 2009.

SCHICK, Steven. Developing an interpretative context: learning Brian Ferneyhough's Bone Alphabet. Perspectives of New Music, Washington, v.32, n 1, p.132-153, Winter, 1994.

\section{Leitura recomendada}

COWELL, Henry. New Musical Resources. New York: Something Else Press, 1930.

FERNEYHOUGH, Brian. The Tactility of Time (Darmstadt Lecture 1988). Perspectives of New Music, Washington, v. 31, $\mathrm{n}^{\circ}$ 1, p.20-30, Winter, 1993.

II Tempo della Figura. Perspectives of New Music, Washington, v. 31, n 1, p.10-19, Winter, 1993.

Form-Figure-Style: An Intermediate Assessment. Perspectives of New Music, Washington, v. 31, $n^{\circ} 1$, p.32-40, Winter, 1993.

HIROKI KOZU, Fernando. A complexidade em Brian Ferneyhough: aspectos de comunicação e inteligibilidade musical. São Paulo: PUC, 2003. (Dissertação de mestrado)

LESTER, Joel. Notated and heard meter. Perspectives of New Music, Washington, v. 24, n² 2, p.116-128, Spring-Summer, 1986. 


\section{Notas}

1 Kampela indica na página 6 do Estudo Percussivo II que a semínima equivale $69 \mathrm{MM}$ ou mais. Para realizar os cálculos optei pela semínima equivalente a $70 \mathrm{MM}$.

2 Para um melhor entendimento do cálculo dos subgrupos ver a tese de doutorado de Arthur Kampela, página 6.

3 Para esses cálculos opta-se pela semínima equivalente a $40 \mathrm{MM}$.

Daniel Vargas é violonista e compositor, aluno do Bacharelado em Violão da Escola de Música e Belas Artes do Paraná (EMBAP), já foi bolsista FAPEMIG de iniciação científica. Participou de um quarteto de violões ao lado de Fábio Adour, com apresentações nas cidades de Belo Horizonte (conservatório da UFMG) e em Ouro Preto (UFOP). Como solista se apresentou no Festival de Inverno de Ouro Preto e Marina. Também, ao lado do compositor e violonista Arthur Kampela se apresentou no Festival Internacional de Violão de Belo Horizonte, (FIV ano V, 2010). 